Hassan Razvi, MD, FRCSC

\section{CUA Secretary and President-Elect}

Cite as: Razvi H. The falling leaves, drift by the window... Can Urol Assoc J 2020;14(10):298. http://dx.doi.org/10.5489/cuaj.6924

Pour la version française, voir cuaj.ca

The CUA exists to promote the highest standard of urologic care for Canadians and to advance the art and science of urology.

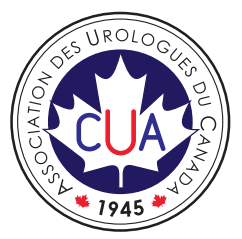

A s I sit in my office writing this piece for CUAJ, September is just days away... where did the summer go? As I expect was the case for most of you, I had no travel vacation this year, but the summer seemed to go by quickly, nevertheless. As the saying goes, "there is always a silver lining" and for me, the opportunity to stay close to home meant catching up on my pleasure reading, getting on my road bike more than I have in years, and tending to my garden. Simple pleasures, but therapeutic, especially given the uncertainty and turmoil in our work lives. I hope all of you had chance to step away from your practices and recharge despite the various COVID restrictions that have disrupted our daily existence.

Although sad to see summer leave us, I sense many of us are looking to the fall with a sense of optimism and renewal. Schools will be opening, and NHL, NBA, and MLB playoffs will be well underway...we hope. As F. Scott Fitzgerald aptly said, "Life starts all over again when it gets crisp in the fall." How appropriate in our current situation!

Your CUA Board and corporate office are looking at the next six months as a time of revitalization. We have several important new initiatives in the works after the summer board meeting - the very first in our organization's storied history to be held virtually. I will briefly mention a few of the projects, with further details to be relayed throughout the year.

- The corporate office continues to roll out the new website and membership database. I would encourage all members to log in to the new site and see the new layout and features. Your feedback is very much welcomed; tell us what you like and what could be improved!

- As part of the website redesign, we have launched UROpedia Canada as the repository of all CUA-endorsed CPD offerings. All the material will be downloadable to members and will offer a one-stop source of up-to-date clinical information from experts in their field.

- A subcommittee of the Board has been established to draft a guiding policy on diversity and equality within our organization. This is both a very timely effort, and incredibly important for the ongoing success and evolution of our organization.

- $\quad$ The Board has agreed in principle to a proposal from the Community Urology Committee to develop a mentorship program grant to provide financial support to community members interested in learning new clinical skills. The Board is committed to ensuring the educational needs of all our members are being met, and this initiative is another example of this pledge.

- The CUAJ Editorial Board is planning to conduct a strategic planning exercise to update the mission, style, and focus of this important vehicle for our organization's influence as "the Voice of Urology in Canada."

On behalf of the Board and Corporate Office, I wish you all a pleasant autumn. Please stay well and take time to sit and watch the leaves turn. 